\title{
A prospective and randomized trial comparing modified and classical techniques of ultrasound-guided thoracolumbar interfascial plane block
}

\author{
Ultrason eşliğinde yapılan torakolomber interfasiyal plan bloğunun klasik ve modifiye \\ tekniklerini karşılaştıran prospektif ve randomize çalışma
}

\author{
Bahadır ÇifTÇi, @ürsel EKiNCi
}

\begin{abstract}
Summary
Objectives: A thoracolumbar interfascial plane (TLIP) block is a novel ultrasound (US)-guided technique that provides effective analgesia after lumbar spinal surgery. Two approaches for a TLIP block have been defined: a classical (cTLIP) technique and a modified (mTLIP) technique. A literature review revealed no published comparison of the 2 techniques. This study examined the practicality and analgesic efficacy of US-guided mTLIP and CTLIP blocks following lumbar disc surgery.

Methods: Sixty patients aged 18-65 years with an American Society of Anesthesiologists classification of I or II who were scheduled for lumbar disc surgery under general anesthesia were included. US-guided mTLIP $(n=30)$ and cTLIP ( $n=30)$ blocks were performed. The performance time of the block procedures, the success of a one-time block, postoperative pain scores, opioid consumption, adverse effects, and block-related complications were recorded and analyzed.

Results: The performance time was significantly less in the MTLIP group $(p<0.001)$. The success of a one-time block was significantly higher in the mTLIP group $(p<0.001)$. The active/passive visual analog scale scores, intraoperative and postoperative opioid consumption, and rescue analgesic requirements were similar between the groups $(p>0.05)$.

Conclusion: The results showed that a US-guided mTLIP block had a shorter performance time and a higher one-time block success rate compared with the CTLIP block. The quality of analgesia provided by the mTLIP and cTLIP blocks was similar.
\end{abstract}

Keywords: Lumbar disc surgery; postoperative analgesia; thoracolumbar interfascial plane block.

\begin{abstract}
Özet
Amaç: Torakolomber interfasiyal plan (TLIP) bloğu, lumbar spinal cerrahi sonrası etkili analjezi sağlayan, ultrason (US) eşliğinde yapılan yeni bir rejyonal anestezi tekniğidir. Bu bloğun iki farklı tekniği tanımlanmıştır: klasik (cTLIP) ve modifiye (mTLIP) teknik. Literatürde henüz bu iki tekniği karşılaştıran bir çalışma bulunmamaktadır. Çalışmamızda lomber disk cerrahisi sonrası US eşliğinde mTLIP ve cTLIP bloklarının işlem uygulama kolaylığını ve analjezik etkinliğini karşılaştırmayı amaçladık.

Gereç ve Yöntem: Amerikan Anestezistler Derneği (American Society of Anesthesiologist/ASA) anestezi risk sınıflamasına göre sınıf I-II, 18-65 yaş arası ve genel anestezi altında lomber disk cerrahisi planlanan 60 hasta çalışmaya dahil edildi. Hastalara US eşliğinde mTLIP ( $n=30)$ ve CTLIP $(n=30)$ blok uygulandı. Blok uygulama süresi, tek seferde blok başarısı, opioid tüketimi, postoperatif ağrı skorları, yan etkiler ve bloğa bağı komplikasyonlar kaydedildi.

Bulgular: Blok uygulama süresi mTLIP grubunda anlamlı derecede düşüktü $(p<0.001)$. Tek seferde blok başarısı mTLIP grubunda anlamlı olarak yüksekti $(p<0.001)$. Intraoperatif ve postoperatif dönemde opioid tüketimi, kurtarıcı analjezik kullanımı ve aktif/pasif VAS skorları gruplar arasında benzerdi ( $p>0.05)$.

Sonuç: Çalışmamızın sonuçlarına göre US eşliğinde yapılan mTLIP blok ve cTLIP blok lomber cerrahi geçiren hastalarda benzer etkinlikte analjezi sağlar. mTLIP blok daha kısa uygulama süresine ve daha yüksek tek girişimde blok başarısına sahiptir.
\end{abstract}




\section{Introduction}

Lumbar spinal surgery is one of the most commonly performed surgeries, and recently the number of spinal surgeries has been increasing. The patients may suffer from moderate-to-severe pain postoperatively. Postoperative pain control is important for patients' early mobilization and recovery. If the acute postoperative pain is not treated effectively, this pain may be transformed into chronic pain. ${ }^{[1,2]} \mathrm{Re}$ gional analgesia techniques may be performed for perioperative and postoperative analgesia management. Thoracolumbar interfascial plane (TLIP) block is a novel technique that is performed under ultrasound (US) guidance using two different approaches: the classical (cTLIP) technique and the modified (mTLIP) technique. ${ }^{[3,4]}$ There exist in the literature several studies about the efficacy of these two approaches. ${ }^{[4-8]}$ However, to date, and to the best of our knowledge, no study has been done that specifically compares the efficacy of the two approaches.

In this trial, we aimed to compare the practicality and analgesic efficacy of the US-guided MTLIP and CTLIP blocks after single-level lumbar disc herniation surgery. The primary aim was to compare block performing times. Secondary aims were to evaluate postoperative pain scores, intraoperative and postoperative opioid consumption, rescue analgesic use, block-related complications (neuroaxial and vascular injury), adverse effects of opioids (breathing depression, sedation, itching, constipation, nausea, and vomiting), and the success of onetime block.

\section{Material and Methods}

This prospective, randomized trial was approved by the local ethics committee, the Clinical Research Ethical Committee of Istanbul Medipol University. After approval, the study was registered at clinicaltrials.gov (registration number: NCT03854240). One day prior to surgery, the study was explained to the patients, including the block procedure, the use of the patient controlled analgesia (PCA) device, and the pain scoring system using the visual analogue scale (VAS), and written informed consents were obtained from the participants for the study. Sixty adult patients ranging from 18 and 65 years of age, classified as being in the American Society of Anesthesiologists (ASA) I-II levels, and scheduled to undergo lumbar disc herniation surgery were included in the present study. The data for this trial were collected from November 2018 to October 2019. The exclusion criteria were the following: allergic reactions to the study drugs (local anesthetic and opioids), being pregnant or lactating, using anticoagulant treatment or having a history of bleeding diathesis, infections in the region of the TLIP block, and refusal of the block procedure and/or study. The study consisted of two groups: the mTLIP group $(n=30)$ and the cTLIP group $(n=30)$. The patients were randomly assigned using the closed envelope method. The study proceeded according to a Consolidated Standards of Reporting Trials (CONSORT) flow diagram chart (Fig. 1).

\section{General anesthesia}

After arrival in the surgery room, a peripheral intravenous (IV) cannula was placed in the patients. The patients were monitored classically according to the standardized ASA monitorization: electrocardiography (ECG), noninvasive blood pressure, and pulse oximetry $\left(\mathrm{SpO}_{2}\right)$. Patients were sedated with an IV dose of $2 \mathrm{mg}$ midazolam. The same general anesthesia protocol was administrated to participants in both groups. The anesthesia induction was performed by using IV propofol (2-2.5 mg/kg), fentanyl (1-1.5 $\mu \mathrm{g} / \mathrm{kg}$ ), and rocuronium bromide $(0.6 \mathrm{mg} / \mathrm{kg})$. After orotracheal intubation was performed, the patients were placed in the prone position for surgery. Anesthesia was maintained with sevoflurane in a mixture of oxygen and fresh air. Remifentanil was administered at an infusion rate of $0.01-0.1 \mu \mathrm{g} / \mathrm{kg} / \mathrm{min}$ for perioperative analgesia regiment. A $4 \mathrm{mg}$ dose of ondansetron IV was applied to all patients. US guided mTLIP and CTLIP blocks were performed before the surgery. The patients' heart rates, respiratory rates, peripheral oxygen saturation, non-invasive arterial pressures, and end-tidal carbon dioxide levels were recorded at 5-min intervals during the operation. Additional analgesia during surgery was provided with $1 \mathrm{mcg} / \mathrm{kg}$ fentanyl and a $50 \%$ increase in sevoflurane concentration if the heart rate and mean arterial pressure of the patient rose above $20 \%$ of baseline. Single-level lumbar discectomy/hemilaminectomy surgery was performed via the same technique by the same surgical team on all the patients. At the end of surgery, the patients were extubated after visualizing sufficient spontaneous respiration. They were then transferred to the postanesthesia care unit (PACU). The patients with a modified Aldrete score of 12 were transferred to the ward. 


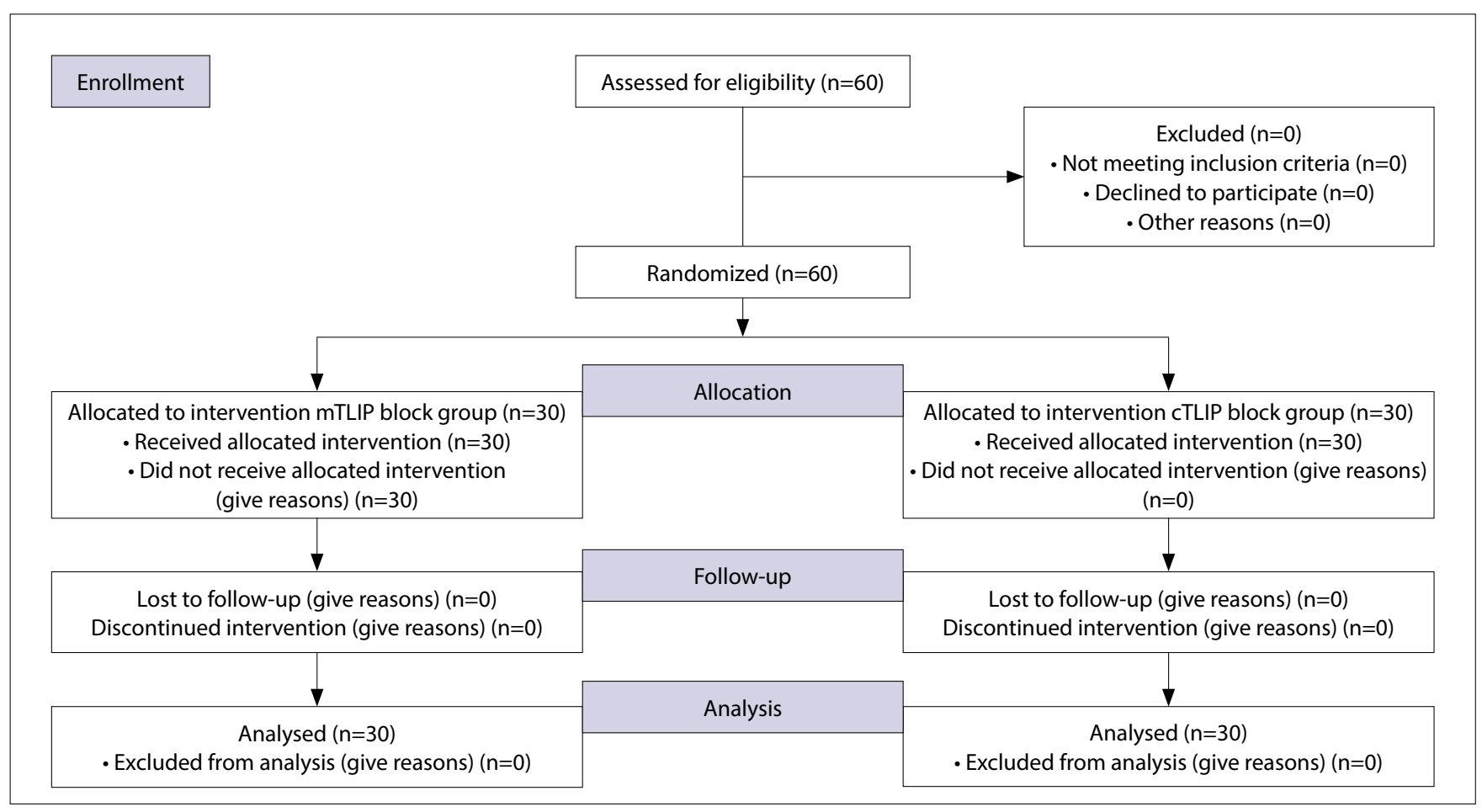

Figure 1. Consort flow diagram of the study.

\section{TLIP block procedure}

After the induction of anesthesia and placement of the patient in a prone position, a US guided mTLIP $(n=30)$ or CTLIP $(n=30)$ block was performed on each patient before the surgery.

All procedures were performed by the same anesthetists. Under aseptic conditions, the blocks were performed bilaterally with a Vivid q US device (GE Healthcare, Wauwatosa, WI, USA) and a high-frequency, $12 \mathrm{MHz}$ linear US probe covered by a sterile sheath. A 22 G, $50 \mathrm{~mm}$ block needle (Stimuplex Ultra 360; B. Braun, Melsungen, Germany) was used for the block procedures. The probe was placed vertically at the $L 3$ vertebrae level. First, the hyperechoic shadow of the spinous process was visualized as an anatomical guide point. Then, the probe was moved laterally to visualize the paraspinal, multifidus (MF), longissimus (LG), and iliocostalis (IC) muscles.

\section{cTLIP block}

In order to discriminate the MF and LG muscles under US, the muscles were compressed by using the probe (Fig. 2). Thus, the interfascial area was visualized during the movement of the muscles due to compression (Fig. 3a). The needle was inserted into the interfascial plane between the MF and LG muscles with an in-plane technique in a lateral-to-medial direction (Fig. 3b). ${ }^{[3]}$

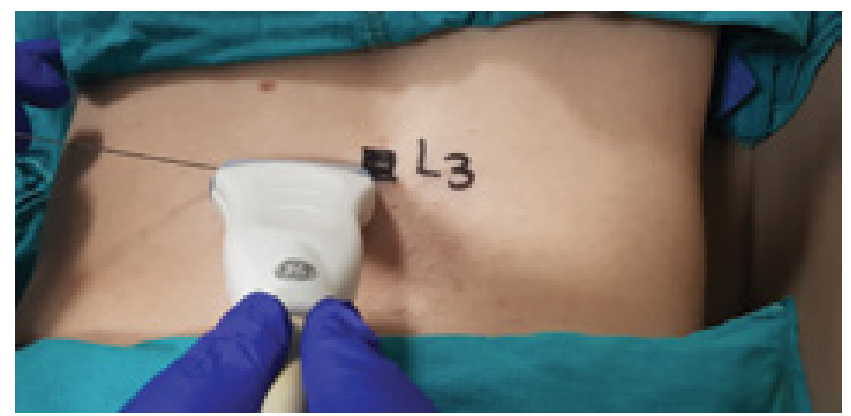

Figure 2. Probe and needle position for CTLIP block.
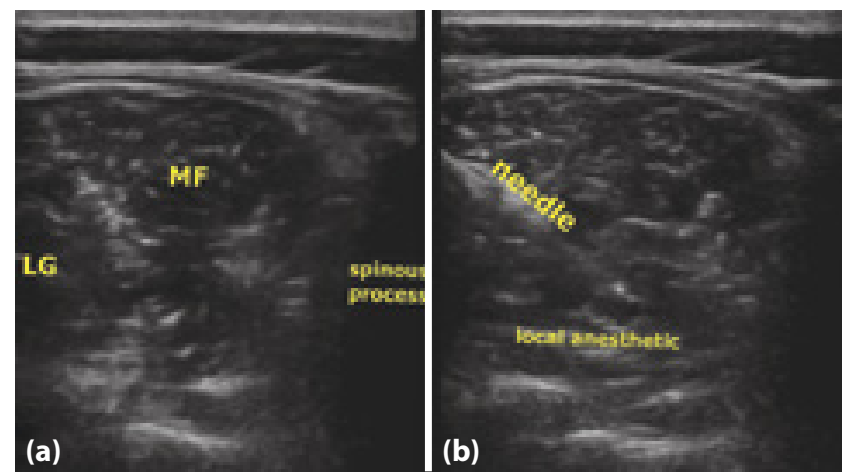

Figure 3. (a) Sonographic anatomy of the CTLIP block. (b) Needle direction and spread of local anesthetic during cTLIP block.

MF: Multifidus muscle; LG: Longissimus muscle. Spinous process is seen.

\section{mTLIP block}

LG and IC muscles were visualized in the lateral compartment of the lumbar region under US (Fig. 4). The needle was inserted into the interfascial plane between the LG and IC muscles using an in-plane technique in a medial-to-lateral direction (Fig. 5a, b). ${ }^{[4,5]}$ 


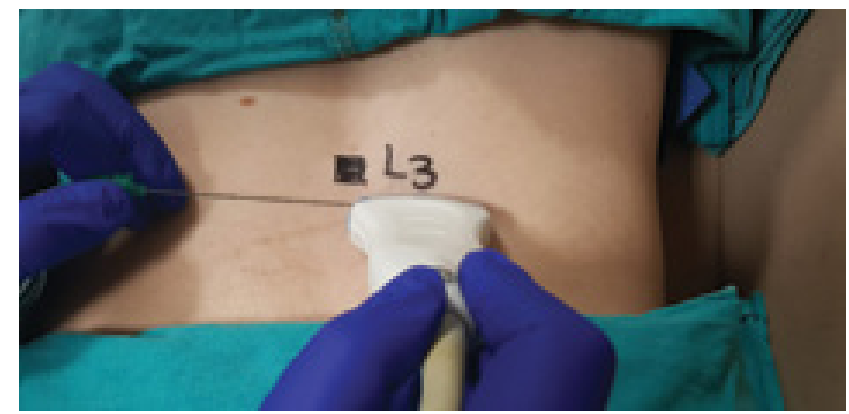

Figure 4. Probe and needle position for mTLIP block.

For both of the groups, when the needle was inserted into the interfascial area, $2 \mathrm{ml}$ of normal saline were injected for correction. A local anesthetic solution included a concentration of $0.25 \%$ bupivacaine injected bilaterally ( $20 \mathrm{ml}$ per each side, a total of 40 $\mathrm{ml}$ ). The performance time of the block procedures and the success of onetime block (successful block with only one entrance of the needle into the tissues and injection of the local anesthetic) were recorded. Block-related complications (neuroaxial and vascular injury) were also recorded.

\section{Postoperative analgesia management}

We used our standardized postoperative analgesia protocol for the study. At $20 \mathrm{~min}$ prior to the end of the surgery, a $1 \mathrm{~g}$ dose of paracetamol and a 100 mg dose of tramadol IV were administered for postoperative analgesia. One gram of paracetamol was intravenously administered every $8 \mathrm{~h}$ in the postoperative period. A fentanyl PCA device was applied to each patient. The PCA protocol was prepared with a $10 \mu \mathrm{g} / \mathrm{mL}$ dose of fentanyl, and the settings were as follows: no infusion dose, a $2 \mathrm{~mL}$ dose of bolus, a lockout time of $20 \mathrm{~min}$, and a 4-hour time limit for a dose of $200 \mu \mathrm{g}$. The passive (i.e., at rest) and active (i.e., while mobilized) pain scores were evaluated by using the VAS ( $0=$ no pain, $10=$ the most severe pain). The VAS scores were recorded at $0,2,4,8,16$, and 24 h postoperatively. A meperidine $(0.5 \mathrm{mg} / \mathrm{kg}) \mathrm{IV}$ was administrated for rescue analgesia if the VAS was $\geq 4$. The postoperative opioid consumption, VAS, rescue analgesia use, and the opioid-related adverse effects (itching, nausea, vomiting, etc.) were evaluated and recorded by a single pain nurse anesthetist who was blinded to the study.

\section{Statistical analysis}

The sample size calculation of the study was performed according to the block procedure time, con-

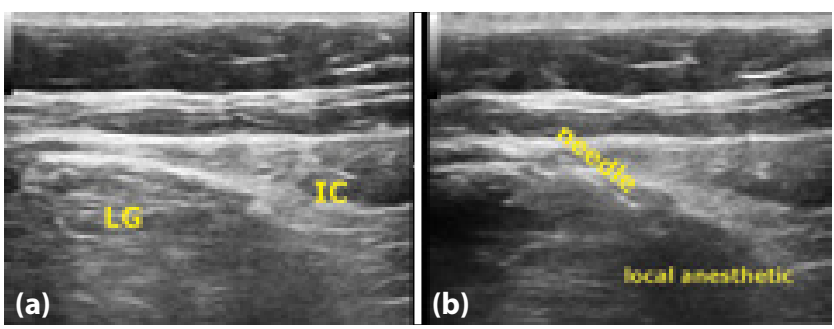

Figure 5. (a) Sonographic anatomy of the mTLIP block. (b) Needle direction and spread of local anesthetic during mTLIP block. IC: Iliocostalis muscle; LG: Longissimus muscle.

sidering that it was the primary outcome of the study. In a previous preliminary study at our clinic, the power of the study was higher than $90 \%$ with an alpha value of 0.05 , when there were 10 patients in each group. This study was completed with 60 patients, 30 patients per each group, for preventing possible data loss. The IBM SPSS Statistics ver. 20.0 (IBM, Armonk, NY, USA) software was used for statistical analyses. The Kolmogorov-Smirnov test was used to evaluate the data distribution. Pearson's chi-square test was applied to categorical data in the groups. Student's t-test was used to check differences between the groups, at a significance level of $5 \%$ for normally distributed continuous variables. Descriptive statistics were expressed as mean \pm standard deviation (SD), and a $\mathrm{p}$ value $<0.05$ was considered statistically significant.

\section{Results}

This study included 60 patients: those who received US-guided CTLIP $(n=30)$ or mTLIP $(n=30)$ blocks. The CONSORT flow diagram chart of this study is displayed in Figure 1. There was no statistical difference between the two groups in terms of demographic data, durations of surgery, and anesthesia $(p>0.05)$. The performance time of the block procedure was significantly lower in the MTLIP group $(7.16 \pm 1.46 \mathrm{~min})$ compared with the cTLIP group $(9.43 \pm 1.79 \mathrm{~min})(p<0.001)$. Success of onetime block was significantly higher in the mTLIP group than in the cTLIP group, 27 vs 12 times, respectively $(p<0.001)$ (Table 1).

Intraoperative and postoperative opioid consumptions at $0-8,8-16$, and $16-24 \mathrm{~h}$ and rescue analgesic use were similar between groups ( $p>0.05$ ) (Table 2). There was no statistical difference in terms of the active/passive VAS scores (Table 3). However, $8^{\text {th }}$ hour active VAS was lower in the MTLIP group compared 
Table 1. Comparison of demographic data between Groups m-TLIP and cTLIP

\begin{tabular}{lccc}
\hline & $\begin{array}{c}\text { Group m-TLIP } \\
(\mathbf{n = 3 0 )}\end{array}$ & $\begin{array}{c}\text { Group cTLIP } \\
(\mathbf{n = 3 0 )}\end{array}$ & p \\
\hline Gender (M/F) & $14 / 16$ & $12 / 18$ & 0.795 \\
Age (years) & $45.67 \pm 9.7$ & $45.93 \pm 10.3$ & 0.919 \\
Weight (kg) & $73.60 \pm 10.588$ & $80.18 \pm 11.21$ & 0.235 \\
Length (cm) & $169.17 \pm 8.83$ & $167.13 \pm 9.68$ & 0.399 \\
ASA I/II & $15 / 15$ & $17 / 13$ & 0.605 \\
Duration of surgery (min) & $81.16 \pm 23.96$ & $71.66 \pm 16.67$ & 0.800 \\
Duration of anesthesia (min) & $99.73 \pm 22.78$ & $94.33 \pm 18.74$ & 0.320 \\
Block procedure time (min) & $7.16 \pm 1.46$ & $9.43 \pm 1.79$ & $<\mathbf{0 . 0 0 1}^{\beta}$ \\
Success of onetime block (yes/no) & $27 / 3$ & $12 / 18$ & $<\mathbf{0 . 0 0 1}^{a}$ \\
\hline
\end{tabular}

Values are expressed mean \pm standart deviation or number. kg: Kilogram; cm: Centimeter; M: Male; F: Female; min: Minutes; ASA: American Society of Anesthesiologist. $\alpha$ : $p<0.05$ Chi-square test between groups; $\beta$ : $p<0.05$ Independent Student's t-test between groups.

Table 2. Comparison of the postoperative fentanyl consumption, intraoperative remifentanil consumption and the use of rescue analgesia (meperidin) between Groups m-TLIP and cTLIP

\begin{tabular}{lccc}
\hline & $\begin{array}{c}\text { Group m-TLIP } \\
(\mathbf{n}=\mathbf{3 0})\end{array}$ & $\begin{array}{c}\text { Group cTLIP } \\
(\mathbf{n = 3 0 )}\end{array}$ & $\mathbf{p}$ \\
\hline $0-8^{\text {th }}$ hours & $29.33 \pm 25.04$ & $22.66 \pm 27.65$ & $0.332^{\beta}$ \\
$8-16^{\text {th }}$ hours & $6 \pm 11.91$ & $5.33 \pm 13.82$ & $0.842^{\beta}$ \\
$16-24^{\text {th }}$ hours & $2.66 \pm 6.91$ & $3.33 \pm 9.22$ & $0.753^{\beta}$ \\
Rescue analgesic using (yes/no) & $23 / 7$ & $21 / 9$ & $0.559^{a}$ \\
Rescue analgesic dose (mg) & $9 \pm 16.23$ & $11.93 \pm 18.54$ & $0.537^{\beta}$ \\
Intraoperative remifentanil consumption (mcg) & $270 \pm 61.02$ & $259.17 \pm 61.75$ & $0.497 \beta$ \\
\hline
\end{tabular}

Values are expressed mean \pm standart deviation or numbers. mg: Miligram; mcg: Microgram; $\alpha: p>0.05$ Chi-square test between groups. $\beta$ : $p>0.05$ Independent Student's T test between groups.

with the cTLIP group ( $\mathrm{p}=0.046)$. In addition, the passive VAS at the $24^{\text {th }}$ hour was lower in the CTLIP group compared with the mTLIP group $(p<0.05)$. There was no intergroup difference in terms of the opioid-related adverse effect profiles ( $p>0.05$ each) (Table 4). There was no block-related complication (neuroaxial and vascular injury) in either of the groups during the study.

\section{Discussion}

This study was designed to compare the practicality and analgesic efficacy of the classic and modified approaches of the TLIP block following lumbar disc herniation surgery. The results showed that the mTLIP block provided a shorter performance time, higher success of onetime block, and similar quality analgesia during the first $24 \mathrm{~h}$ when compared with the cTLIP block after surgery.
The TLIP block is a novel technique that may provide effective analgesia for lumbar and low back pain. [3,7,9-12] It was first described as the classical approach by Hand ${ }^{[3]}$ et al. in 2015. In this method, a local anesthetic solution is injected into the interfascial area between the MF and LG muscles at the level of the third lumbar vertebrae. In 2017, Ahiskalioglu et al. ${ }^{[4,5]}$ described a novel modified approach for the US guided TLIP block, the mTLIP block. In this modified technique, a local anesthetic solution is injected into the interfascial area between the LG and IC muscles. However, to the best of our knowledge, there is no study that compares these two approaches except for our current one. Our results showed that the mTLIP block had a shorter performance time and higher success of onetime block than the cTLIP block.

Hand et al. reported that the visualization and especially discrimination of the MF and LG muscles 
Table 3. Comparison of the visual analogue scale (VAS) scores between Groups m-TLIP and cTLIP

\begin{tabular}{cccc}
\hline Hour & $\begin{array}{c}\text { Group } \mathbf{m} \text {-TLIP } \\
(\mathbf{n}=\mathbf{3 0})\end{array}$ & $\begin{array}{c}\text { Group cTLIP } \\
(\mathbf{n}=\mathbf{3 0})\end{array}$ & $\mathbf{p}$ \\
\hline VAS passive & & & \\
0 & $1.47 \pm 1.43$ & $1.37 \pm 1.24$ & 0.774 \\
2 & $1.8 \pm 1.09$ & $1.3 \pm 1.2$ & 0.098 \\
4 & $1.17 \pm 0.87$ & $1.3 \pm 0.91$ & 0.566 \\
8 & $0.77 \pm 0.81$ & $1.03 \pm 0.76$ & 0.197 \\
16 & $0.97 \pm 0.76$ & $1.03 \pm 0.8$ & 0.744 \\
24 & $0.37 \pm 0.49$ & $0.13 \pm 0.34$ & $\mathbf{0 . 0 3 7}$ \\
VAS active & & & \\
0 & $2.2 \pm 1.47$ & $2.43 \pm 1.61$ & 0.560 \\
2 & $2.37 \pm 1.21$ & $1.97 \pm 1.21$ & 0.208 \\
4 & $1.63 \pm 0.99$ & $1.83 \pm 1.05$ & 0.454 \\
8 & $1.1 \pm 0.66$ & $1.47 \pm 0.73$ & $\mathbf{0 . 0 4 6}$ \\
16 & $1.2 \pm 0.8$ & $1.2 \pm 1.03$ & 1 \\
24 & $0.47 \pm 0.57$ & $0.5 \pm 0.68$ & 0.838 \\
\hline
\end{tabular}

Values are expressed mean \pm standart deviation. VAS: Visual analog pain scale; $a: p<0.05$ Independent Student's T test between groups.

may be difficult under US. ${ }^{[3]}$ These muscles may be visualized as a single large muscle. To prevent this, we compressed the probe above the MF and LG. Thus, the interfascial area was visualized during the movement due to the compression. However, during the application of mTLIP block, the visualization of the LG and IC muscles and the discrimination of the target interfascial plane was easier and simpler. Our results showed that the performance time of the mTLIP block was shorter than that of the CTLIP block because of this. At the same time, the success of onetime block was higher in the mTLIP block group than in the cTLIP block group.

With the CTLIP block, the needle is directed through the neuroaxial structures in a lateral-to-medial direction ${ }^{[5]}$ However, with the mTLIP block, the needle is in the medial-to-lateral direction. ${ }^{[4,5]}$ Thus, with the mTLIP block, the neuraxial structures are not in the target of the needle tip. ${ }^{[1]]}$ In our study, there was no block-related complication in either group.

The spinal nerve divides into two rami after leaving the intervertebral foramen: the larger one is the ventral ramus, and the smaller one is the dorsal ramus. The dorsal ramus runs around the facet joints, innervates ligaments, joints, and paraverte-
Table 4. The Comparison of incidence of adverse effects between Groups m-TLIP and cTLIP

\begin{tabular}{lccc}
\hline & $\begin{array}{c}\text { Group } \\
\mathbf{m}-\text { TLIP } \\
(\mathbf{n}=\mathbf{3 0})\end{array}$ & $\begin{array}{c}\text { Group } \\
\mathbf{c T L I P} \\
(\mathbf{n}=\mathbf{3 0})\end{array}$ & $\mathbf{p}$ \\
\hline Breathing depression & 0 & 0 & $1^{\mathrm{a}}$ \\
Sedation/confusion & 0 & 0 & $1^{\mathrm{a}}$ \\
Urinary retention & 0 & 0 & $1^{\mathrm{a}}$ \\
Nausea (N/Y) & $27 / 3$ & $28 / 2$ & $0.640^{a}$ \\
Vomiting (N/Y) & $27 / 3$ & $28 / 2$ & $0.640^{a}$ \\
Itching (N/Y) & $4 / 26$ & $7 / 23$ & $0.506^{a}$ \\
Constipation & 0 & 0 & $1^{a}$ \\
\hline
\end{tabular}

$a: p>0.05$ Chi-square test between groups; N: No; Y: Yes.

bral muscles and provides cutaneous sense from the vertex to the coccyx..$^{[12,13]}$ The thoracolumbar interfascial plane block targets the dorsal rami of the thoracolumbar nerves. ${ }^{[13,14]}$ In the literature, it has been reported that both the cTLIP block and the MTLIP block provide effective analgesia management following different lumbar spinal surgery procedures. ${ }^{[12-19]}$ The results of our trial showed that the two approaches provided similar effective analgesia after lumbar disc surgery.

The present trial had some limitations. First, we did not perform dermatomal sensory testing because the blocks were performed after the general anesthesia induction; this could be used to better understand the efficacy areas of the two blocks. Second, it would have been useful to add a contrast medium to the mixture of local anesthetic, followed by an anteroposterior X-ray, to understand the spread of the injectate. Lastly, our study did not have a control group. These limitations may be avoided in future studies.

\section{Conclusion}

In summary, clinicians generally prefer either mTLIP or CTLIP for pain control after lumbar spinal surgery based on their personal clinical experience. However, our study showed that US guided mTLIP block had a shorter performance time and higher success of onetime block compared with the cTLIP block.

Ethics Committee Approval: The Istanbul Medipol University Clinical Research Ethics Committee granted approval for this study (date: 28.12.2018, number: 25). 
Conflict-of-interest issues regarding the authorship or article: None declared.

Peer-rewiew: Externally peer-reviewed.

\section{References}

1. McGirt MJ, Ambrossi GL, Datoo G, Sciubba DM, Witham TF, Wolinsky JP, et al. Recurrent disc herniation and long-term back pain after primary lumbar discectomy: review of outcomes reported for limited versus aggressive disc removal. Neurosurgery 2009;64(2):344-5. [CrossRef]

2. Efthymiou CA, O'Regan DJ. Postdischarge complications: what exactly happens when the patient goes home? Interact Cardiovasc Thorac Surg 2011;12(2):130-4. [CrossRef]

3. Hand WR, Taylor JM, Harvey NR, Epperson TI, Gunselman RJ, Bolin ED, et al. Thoracolumbar interfascial plane (TLIP) block: a pilot study in volunteers. Can J Anaesth 2015;62(11):1196-200. [CrossRef]

4. Ahiskalioglu A, Yayik AM, Alici HA. Ultrasound-guided lateral thoracolumbar interfascial plane (TLIP) block: Description of new modified technique. J Clin Anesth 2017;40:62.

5. Ahiskalioglu A, Alici HA, Selvitopi K, Yayik AM. Ultrasonography-guided modified thoracolumbar interfascial plane block: a new approach. Can J Anaesth 2017;64(7):775-6.

6. Li C, Jia J, Qin Z, Tang Z. The use of ultrasound-guided modified thoracolumbar interfascial plane (TLIP) block for multilevel lumbar spinal surgery. J Clin Anesth 2018;46:49-51.

7. Ueshima $\mathrm{H}$, Ozawa $\mathrm{T}$, Toyone $\mathrm{T}$, Otake $\mathrm{H}$. Efficacy of the Thoracolumbar Interfascial Plane Block for Lumbar Laminoplasty: A Retrospective Study. Asian Spine J 2017;11(5):722-5. [CrossRef]

8. Ueshima $\mathrm{H}$, Otake $\mathrm{H}$. Clinical efficacy of modified thoracolumbar interfascial plane block. J Clin Anesth 2016;30:745. [CrossRef]

9. Ahiskalioglu A, Yayik AM, Doymus O, Selvitopi K, Ahiskalioglu EO, Calikoglu C, et al. Efficacy of ultrasound-guided modified thoracolumbar interfascial plane block for postoperative analgesia after spinal surgery: a randomized- controlled trial. Can J Anaesth 2018;65(5):603-4. [CrossRef]

10. Ahiskalioglu A, Yayik AM, Celik EC, Aydin ME, Uzun G. UItrasound guided modified Thoracolumbar Interfascial Plane block for low back pain management. J Clin Anesth 2019;54:138-9. [CrossRef]

11. Ueshima $\mathrm{H}$, Otake $\mathrm{H}$. Ultrasound-guided thoracolumbar interfascial plane block: Complications in 175 consecutive cases. J Clin Anesth 2019;58:5-6. [CrossRef]

12. Ueshima H, Oku K, Otake $\mathrm{H}$. Ultrasound-guided thoracolumbar interfascial plane block: a cadaveric study of the spread of injectate. J Clin Anesth 2016;34:259-60. [CrossRef]

13. Ueshima $H$, Hara $E$, Otake $H$. Thoracolumbar interfascial plane block provides effective perioperative pain relief for patients undergoing lumbar spinal surgery; a prospective, randomized and double blinded trial. J Clin Anesth 2019;58:12-7. [CrossRef]

14. Ueshima $\mathrm{H}$, Otake $\mathrm{H}$. Ultrasound-guided "lateral" thoracolumbar interfascial plane (TLIP) block: A cadaveric study of the spread of injectate. J Clin Anesth 2017;40:54. [CrossRef]

15. Ueshima $H$, Otake $H$. Clinical experiences with s combination of thoracolumbar interfascial plane (TLIP) with modified TLIP blocks. J Clin Anesth 2019;54:2. [CrossRef]

16. Hamilton DL. Does Thoracolumbar Interfascial Plane Block Provide More Focused Analgesia Than Erector Spinae Plane Block in Lumbar Spine Surgery? J Neurosurg Anesthesiol. doi: 10.1097/ANA.0000000000000643. [Epub ahead of print] [CrossRef]

17. Xu JL, Doherty T, Patel R, Galeno J, Dotzauer B. Analgesic efficacy of ultrasound-guided modified thoracolumbar interfascial plane block performed with the use of neurophysiology monitoring for postoperative lumbar surgery. J Clin Anesth 2019;52:21-3. [CrossRef]

18. Xu JL, Tseng V. Proposal to standardize the nomenclature for paraspinal interfascial plane blocks. Reg Anesth Pain Med. doi: 10.1136/rapm-2019-100696. [Epub ahead of print] [CrossRef]

19. Ueshima H. Lumbar thoracolumbar interfascial plane block provides effective analgesia for spondylosis. J Clin Anesth. doi: 10.1016/j.jclinane.2019.03.005. [Epub ahead of print] 